\title{
Relationship of Chemical-Based Effluent Regulations of Korea to Aquatic Toxicities to Microbes, Macroinvertebrates, and Fish
}

\author{
K. Choi, ${ }^{1}$ P. G. Meier, ${ }^{2}$ M. Zong ${ }^{1}$ \\ 1 Institute of Health and Environment, School of Public Health, Seoul National \\ University, 28, Yunkeon, Chongro, Seoul, 110-799, Korea \\ 2 Department of Environmental Health Sciences, School of Public Health, University \\ of Michigan, 109 South Observatory, Ann Arbor, MI 48109, USA
}

Received: 15 September 2003/Accepted: 22 January 2004

Currently in Korea, like in many developing countries, environmental regulations for effluent management have been solely based on the chemistry-based approach. The Permissible Wastewater Discharge Standards (PWDSs) of Korea describe maximum allowable concentrations of a total of 28 items which include a number of heavy metals (e.g., $\mathrm{As}, \mathrm{Cd}, \mathrm{Cr}, \mathrm{Cu}, \mathrm{Fe}, \mathrm{Hg}, \mathrm{Pb}, \mathrm{Zn}$, etc), organic contaminants (e.g., PCBs, phenol, trichloroethylene, tetrachloroethylene, etc), physicochemical parameters (e.g., color, $\mathrm{pH}$, temperature, etc), and a few water quality parameters (e.g., BOD, COD, and total suspended solids). This regulatory approach has limitations because of effluents' diverse chemical composition, complicated interactions among their constituents, and the lack of information on the bioavailability of chemicals (US EPA 1991).

The focus of water quality management in Korea is moving toward protection of aquatic ecosystems (Korea Ministry of Environment Web, logged on April 2003). One approach to achieve this would be to incorporate biological measures (i.e., whole effluent toxicity testings, etc) into regulatory context (Korea Ministry of Environment 2002) and another approach would be incorporating additional chemicals or physical parameters of concern into the regulation.

Only a limited number of studies have been conducted suggesting limitations of chemistry-only regulatory approach in Korea for effluent control. Lee and others (1991) showed that reliance on a few water quality parameters such as BOD and COD was not sufficient enough to protect aquatic organisms from acute biological impact. A recent study (Korea Ministry of Environment 2002) also showed chemical parameters under regulation were not indicative of biological responses. Both works were focused only on acute lethal impacts. Choi and Meier (2000) indicated the chemistry-oriented effluent regulations could not protect teleosts from DNA damage due to exposure to metal contaminants. Studies investigating how addition of new parameters in the regulation improves the protection of aquatic biota are also hard to locate.

In this study, we conducted acute and chronic toxicity assays employing microbes, macroinvertebrates, and fish for a specific group of wastewater samples of which 
the contaminants' profiles were rather similar. Chemical analyses were concurrently performed and regulation compliances of these samples were determined. With these, we evaluated whether there was a need for supplementing the chemical-specific Korean regulation with a biological measure. In addition, benefits of expanding the list of chemical parameters under regulation were assessed in terms of prediction of potential impact on aquatic biota.

\section{MATERIALS AND METHODS}

Eleven metal plating wastewater samples were collected from two metal plating facilities located in Michigan, USA. Samples included untreated wastewater, partially treated wastewater, and effluent. The reason for taking samples from these different points was to secure a broad range of contaminant concentrations. Samples were collected in 19-L cubitainers and transported to the laboratory (Ann Arbor, MI, USA). Upon arrival, a volume of sample was removed for physicochemical analyses and the remaining portion was utilized for toxicity evaluation. The samples were initially analyzed for total residual chlorine and $\mathrm{pH}$. If residual chlorine was present, it was oxidized with sodium thiosulfate: Sample IDs 3 and 9 from which residual chlorine of 120 and $170 \mathrm{ug} / \mathrm{L}$ were detected, respectively, were dechlorinated. Since sodium thiosulfate may alter the toxicity of an effluent sample through chelation of metal species in it (Hockett and Mount 1996), extra care was taken to ensure the use of appropriate amount following US EPA (2002a). US Environmental Protection Agency (US EPA) indicates aquatic toxicity may occur due to $\mathrm{pH}$ alone if the $\mathrm{pH}$ of the sample falls outside the range of 6-9 $(2002 a, 2002 b)$. For Sample IDs 2 and 10 of which pH were 9.3 and 11.8, respectively, $\mathrm{pH}$ was adjusted to approximately 7.0 by adding $1 \mathrm{~N} \mathrm{HCl}$ dropwise. Adjusted $\mathrm{pH}$ was well maintained throughout the test periods. The samples were also evaluated for ammonia, alkalinity, hardness, dissolved oxygen, and specific conductivity. Moderately hard water, synthesized in accordance with the US EPA guidelines $(2002 a, 2002 b)$, was used for the maintenance of test organisms and for dilution in preparation of exposure concentrations.

The samples were analyzed for various pollutants following either American Public Health Association (APHA) Standard Methods (1992) or US EPA analytical standard methods. Analytes encompassed the regulated items in the Korean Water Quality Preservation Act. Ammonia, pH, and residual chlorine were determined by respective ion specific electrodes. Spectrophotometry was used to determine concentrations of hexavalent chromium and cyanide. Mercury was analyzed with cold vapor atomic absorption spectrophotometry, and metal species such as $\mathrm{Cd}, \mathrm{Cr}, \mathrm{Cu}, \mathrm{Fe}, \mathrm{Pb}$, and $\mathrm{Zn}$ were determined with inductively coupled argon plasma atomic emission spectroscopy.

Microtox Model 500 Toxicity Analyzer was used for the microbial assay. Lyophilized Vibrio fischeri reagent was obtained from Azur Environmental (now SDI, Newark, DE, USA). The test procedures employed were "Basic" and "100\%" protocols as described in Microbics Corp. (1992). The bacteria were exposed to series of sample concentrations for $30 \mathrm{~min}$ at $15{ }^{\circ} \mathrm{C}$. Two 
macroinvertebrates, i.e., Daphnia magna and Ceriodaphnia dubia used for acute and chronic toxicity tests, respectively, were cultured and maintained in house. Larval Pimephales promelas (fathead minnows) were employed for acute and chronic tests and were purchased from Aquatox Inc. (Hot Springs, AR, USA). All aspects of the culture and maintenance of test organisms were in accordance with US EPA guidelines $(2002 a, 2002 b)$. Acute tests were conducted for all eleven samples; however, chronic tests were performed with only part of them $(n=5)$. Acute and chronic reference tests were run to assure comparable sensitivities of the test species over time (results not shown).

The E(L)C50 (Median Effect/Lethal Concentration) and the IC25 values (Inhibition Concentration causing 25\% impact in nonlethal measurement) were determined for acute and chronic tests, respectively. For the EC50s of the Microtox assay, a vendor provided software was applied. The E(L)C50s for the acute daphnids/fish toxicity tests were calculated using TOXSTAT program (version 3.5, West Inc., West Cheyenne, WY, USA). The IC25 values of the chronic toxicity tests were calculated by ICp approach of US EPA (version 2.0, US EPA, Duluth, MN, USA; Norberg-King 1993). The Fisher's Exact Test and the test of agreement were conducted using SPSS (version 7.0, SPSS, Chicago, IL, USA).

\section{RESULTS AND DISCUSSION}

The chemical constituents of each sample are presented in Table 1. Various toxic endpoints determined for these samples are summarized in Table 2. In all samples, acute Daphnia toxicity test showed a greater susceptibility to metal-rich wastewater than the Microtox or the acute fish test. This trend has been demonstrated with samples rich in inorganics including heavy metals (Munkittrick et al. 1991). A similar pattern was observed also in chronic test results (Table 2).

Chemical pollutants were initially confined only to three general water quality parameters, i.e., BOD, COD, and TSS, which have been widely utilized by wastewater treatment plants (WWTPs) to evaluate their treatment performances. Out of nine waste samples which were in compliance with the regulation, three samples (i.e., Sample IDs 3, 9, and 10) showed acute impact on daphnids and fish. With the Microtox assay, microbial toxicity was found in two samples which did not exceed the chemistry-based standards (i.e., Sample IDs 3 and 9). This discrepancy was also observed with the chronic daphnid and fish tests in one and two samples, respectively, out of three samples which were not in exceedance of PWDSs.

When all the contaminants potentially present in the samples were incorporated into the chemistry data, the regulation compliance corresponded better with the toxicity test results: Only one out of six samples that complied with the regulatory limits elicited acute toxicities in daphnids and fish (i.e., Sample ID 10). With chronic data, one out of two complied samples (i.e., Sample ID 4) showed serious 
Table 1. Concentration of regulated pollutants from metal plating wastewater samples.

\begin{tabular}{lcccccccc}
\hline $\begin{array}{c}\text { Sample } \\
\text { ID }\end{array}$ & $\begin{array}{c}\text { BOD } \\
(120)\end{array}$ & $\begin{array}{c}\text { COD } \\
(130)\end{array}$ & $\begin{array}{c}\text { TSS } \\
(120)\end{array}$ & $\begin{array}{c}\mathrm{Cr} \\
(2)\end{array}$ & $\begin{array}{c}\mathrm{Cr}^{6+} \\
(0.5)\end{array}$ & $\begin{array}{c}\mathrm{Cu} \\
(3)\end{array}$ & $\begin{array}{c}\mathrm{Fe} \\
(10)\end{array}$ & $\begin{array}{c}\mathrm{Zn} \\
(5)\end{array}$ \\
\hline 1 & 93 & 620 & 156.6 & 14.7 & 0.18 & 12.8 & 17.0 & 81.6 \\
2 & 106 & 470 & 4.7 & 3.1 & 2.81 & 0.32 & 0.07 & 0.35 \\
3 & 7 & 55 & 29.4 & 65.0 & 62.1 & 1.60 & 2.66 & 0.65 \\
4 & 20 & 50 & 5.5 & 0.29 & $<0.01$ & $<0.05$ & 0.06 & $<0.05$ \\
5 & $<2$ & $<5$ & 6.3 & $<0.05$ & $<0.01$ & $<0.05$ & 1.34 & $<0.05$ \\
6 & $<2$ & $<5$ & 35 & 0.31 & $<0.01$ & 0.36 & 8.59 & 0.44 \\
7 & 4.8 & 5 & 47.8 & 0.40 & $<0.05$ & 0.23 & 10.4 & 2.19 \\
8 & $<2$ & $<5$ & 4.8 & $<0.05$ & $<0.05$ & $<0.05$ & 1.48 & $<0.05$ \\
9 & $<2$ & $<5$ & 56.3 & 103.6 & 99.0 & 3.15 & 6.15 & $<0.5$ \\
10 & 2.5 & 110 & 2.1 & 0.21 & $<3.0$ & $<0.05$ & 0.28 & $<0.05$ \\
11 & 1.5 & 5 & 4.9 & 0.13 & $<0.005$ & $<0.05$ & 1.31 & $<0.05$ \\
\hline Concen & $<$ & 5 & &
\end{tabular}

Concentrations in $\mathrm{mg} / \mathrm{L}$ : Values in parentheses are PWDSs. There are several sets of PWDSs depending on daily discharge rate and the designated class of receiving water body. PWDSs presented here are a most widely applied set in Korea: $\mathrm{Cd}, \mathrm{Hg}, \mathrm{Pb}$ and $\mathrm{CN}$ were not detected. Detection limit for $\mathrm{Cd}$ and $\mathrm{Pb} 0.05 \mathrm{mg} / \mathrm{L}, \mathrm{Hg} 0.0002 \mathrm{mg} / \mathrm{L}$, and $\mathrm{CN}$ $0.01 \mathrm{mg} / \mathrm{L}$.

Table 2. Toxicity endpoints and corresponding confidence intervals derived from acute and chronic tests.

\begin{tabular}{|c|c|c|c|c|c|}
\hline \multirow{4}{*}{$\begin{array}{l}\text { Sample } \\
\text { ID }\end{array}$} & \multicolumn{3}{|c|}{ Acute Test } & \multicolumn{2}{|c|}{ Chronic Test } \\
\hline & Microtox & D. magna & P.promelas & C. dubia & P. promelas \\
\hline & $30-\mathrm{min}$ & 48-hr & $96-\mathrm{hr}$ & $7-d$ & $7-d$ \\
\hline & EC50 & EC50 & LC50 & IC25 & IC25 \\
\hline 1 & 0.9 & 0.06 & 3.0 & 0.16 & 0.2 \\
\hline & $(0.8-1.1)$ & $(0.04-0.09)$ & $(2.4-3.8)$ & $(0.16-0.17)$ & $(0.1-0.9)$ \\
\hline 2 & 51.8 & 7.2 & 56.8 & 3.2 & 13.7 \\
\hline & $(48.7-55.2)$ & $(6.0-8.7)$ & $(49.4-65.2)$ & $(2.9-3.9)$ & $(4.1-32.3)$ \\
\hline 3 & 31.0 & 0.02 & 12.79 & 0.007 & $>5$ \\
\hline & $(28.7-33.4)$ & $(0.01-0.02)$ & $(11.3-14.5)$ & $(0.006-0.009)$ & \\
\hline 4 & $>90$ & $>100$ & $>100$ & $\begin{array}{c}1.5 \\
(0.7-3.0)\end{array}$ & $>100$ \\
\hline 5 & $>90$ & $>100$ & $>100$ & $>100$ & $>100$ \\
\hline 6 & $>90$ & $>100$ & $>100$ & NP & NP \\
\hline 7 & $>90$ & $>100$ & $>100$ & NP & NP \\
\hline 8 & $>90$ & $>100$ & $>100$ & NP & NP \\
\hline 9 & $\begin{array}{c}77.2 \\
(62.6-95.2)\end{array}$ & $\begin{array}{c}0.01 \\
(0.01-0.02)\end{array}$ & $\begin{array}{c}88.9 \\
(77.1-102.5)\end{array}$ & NP & NP \\
\hline 10 & $>90$ & $\begin{array}{c}43.0 \\
(35.9-51.5)\end{array}$ & $\begin{array}{c}75.2 \\
(70.9-79.7)\end{array}$ & NP & NP \\
\hline 11 & $>90$ & $>100$ & $>100$ & NP & NP \\
\hline
\end{tabular}

Values in percent concentration of sample: Values in parentheses are $95 \%$ confidence interval: $\mathrm{NP}=\mathrm{Not}$ Performed. 
Table 3. Relationship between regulation compliance with PWDSs for three major water quality parameters and aquatic toxicity.

\begin{tabular}{lcc}
\hline $\begin{array}{l}\text { Regulation Compliance } \\
\text { versus }\end{array}$ & $\begin{array}{c}\text { Fisher's Exact Test } \\
\text { Exact sig. (2 tailed) }\end{array}$ & Kappa \\
\hline Microtox Toxicity & 0.11 & 0.56 \\
Acute $D$. magna Toxicity & 0.18 & 0.42 \\
Acute $P$. promelas Toxicity & 0.18 & 0.42 \\
Chronic $C$. dubia Toxicity & 1.00 & 0.29 \\
Chronic P. promelas Toxicity & 0.40 & 0.62 \\
\hline
\end{tabular}

${ }^{\mathrm{a}}$ Water quality parameters utilized in this comparison were confined to BOD, COD, and TSS.

reproductive failure in $C$. dubia. The results suggest that acute and chronic impact may be better prevented by regulating more chemical parameters. However, it should be noted that chance of overlooking potentially toxic effluents is present, which could cause adverse consequences in aquatic ecosystems (see Sample IDs 4 and 10).

The dependence and the degree of agreement between chemical and biological observations were evaluated by the Fisher's Exact Test and the Cohen's kappa value, a chance-corrected measure of agreement (Fleiss 1981). For this purpose, samples were dichotomously classified depending upon their compliance with the regulation ("exceedance" or "non-exceedance"). In addition, based on the result of the toxicity tests, samples were separated arbitrarily into two categories: Those which showed adverse effects (i.e., E(L)C50 or IC25) below $100 \%$ were categorized as "toxic" group, while the others were designated as "non-toxic". When only three pollution parameters were considered (Table 3), the results of the Fisher's Exact Test demonstrated that none of the acute and chronic toxicity tests related with regulation compliance $(\mathrm{p}>0.10)$. The Cohen's kappa showed that the regulation compliances with PWDSs of the three water quality parameters exhibited only marginally fair agreement with the acute Daphnia test and fish test (kappa =0.42). Kappa values between 0.4 and 0.75 represent fair to good agreement beyond chance, while values below 0.4 represent poor agreement (Landis and Koch 1977). With the Microtox assay and the chronic fish test, regulation compliances with three water quality parameters showed fair to good degree of agreement (kappa $\approx 0.60$ ). For the chronic Ceriodaphnia test, a poor agreement was found (kappa $=0.29)$.

When the analytical results of various metal species were added, all toxicity tests, with an exception of the chronic Ceriodaphnia assay, showed a dependency on the regulation compliance $(\mathrm{p}<0.10)$. Better agreement was found also by Cohen's kappa values (Table 4): The regulation compliance showed improved agreement with the acute daphnid and minnow test $($ kappa $=0.63)$. The lowest kappa value of 0.55 observed with chronic daphnid results still represents fair agreement. 
Table 4. Relationship between regulation compliance with PWDSs for comprehensive chemical parameters and aquatic toxicity.

\begin{tabular}{lcc}
\hline $\begin{array}{c}\text { Regulation Compliance }^{\mathrm{a}} \\
\text { Versus }\end{array}$ & $\begin{array}{c}\text { Fisher's Exact Test } \\
\text { Exact sig. }(2 \text { tailed })\end{array}$ & Kappa \\
\hline Microtox Toxicity & $0.02^{\mathrm{b}}$ & 0.81 \\
Acute $D$. magna Toxicity & $0.01^{\mathrm{b}}$ & 0.63 \\
Acute P. promelas Toxicity & $0.01^{\mathrm{b}}$ & 0.63 \\
Chronic C. dubia Toxicity & 0.40 & 0.55 \\
Chronic P. promelas Toxicity & $0.10^{\mathrm{b}}$ & 1.00
\end{tabular}

${ }^{a}$ Chemical parameters utilized for the comparison incorporated all contaminants expected to be present in the subject samples.

b The exact probability of obtaining the observed result or the more extreme, if the two variables are independent, is less than 0.10 .

Table 5. Sensitivity and specificity of chemical-specific regulation to indicate aquatic toxicity.

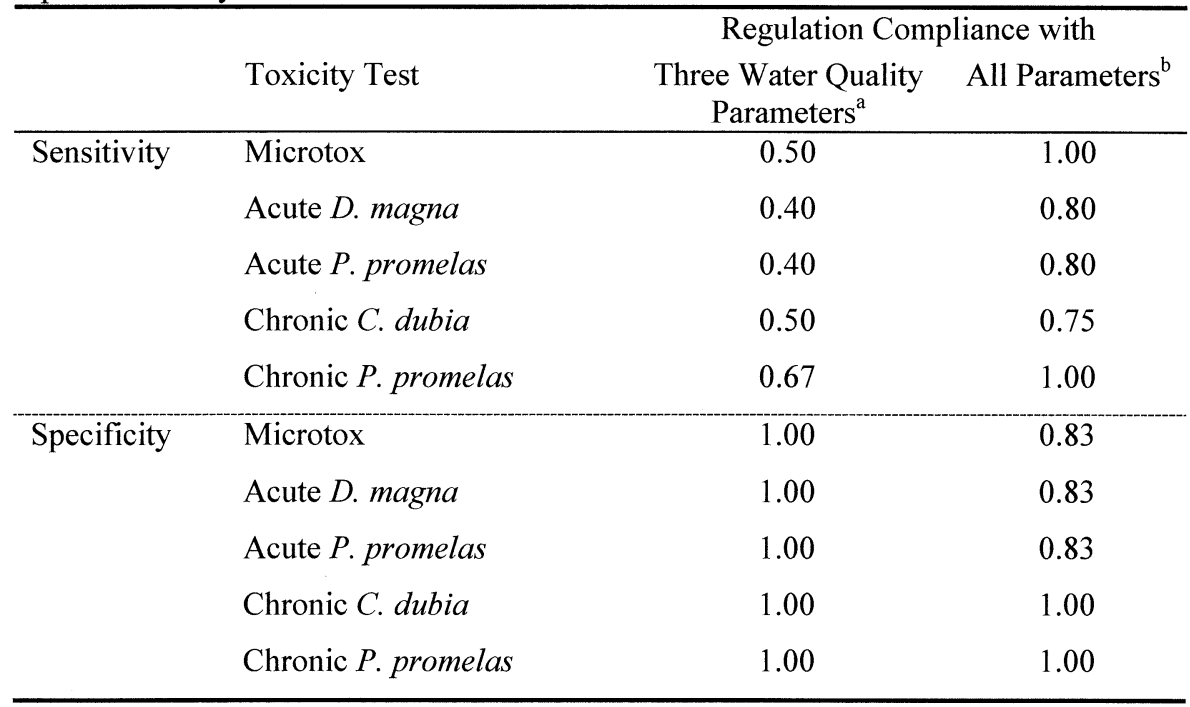

${ }^{\mathrm{a}} \mathrm{BOD}, \mathrm{COD}$, and TSS.

${ }^{\mathrm{b}}$ All chemical parameters expected to be present in the subject samples.

According to these statistical analyses, the chemical-specific regulation corresponded better with the biological toxicity when the number of pollutant parameters under regulation was increased.

The sensitivity and specificity of the chemical-specific regulation compliance were evaluated for each of the biological toxicity tests (Table 5). The chemicalspecific approach utilizing all physical-chemical parameters resulted in sensitivities that ranged from $75 \%$ to $100 \%$ (average $87 \%$ ) for detecting acute and chronic effects; whereas, an average of $49 \%$ was observed when only three major 
water quality parameters were considered. This would suggest that chemicalspecific approach, when properly incorporating all the potential contaminants, was better able to detect wastes that were toxic to aquatic organisms. On the other hand, the specificity was reduced from $100 \%$ to an average of $90 \%$ after adding more parameters under consideration. This implies that an increase in analyte number does not necessarily improve the accuracy of overall prediction of effluent toxicity; it is possible to over-emphasize the impact of an effluent on the aquatic biota.

To extend this comparison further, we attempted to estimate chemical concentrations in samples with toxicities amounting to E(L)C50 or LC25 at $100 \%$ (without dilution), by multiplying the metal concentrations in the sample by the percent dilution at the $\mathrm{E}(\mathrm{L}) \mathrm{C} 50$ or IC25. Then the calculated chemical concentrations of a sample were compared to the regulated limits (calculations not shown). Among samples showing acute and chronic Daphnia toxicities originally, all samples except Sample ID 10 (Sample IDs 1, 2, 3, and 9) exhibited daphnid toxicities (EC50 or IC25) even when the estimated chemical concentrations were below the regulatory limits. In addition, significant reductions in the chronic fish growth rate were detected from Sample IDs 1 and 2 of which estimated metal concentrations did not exceed the numeric criteria.

An expansion of chemical parameters may appear to provide better protection of aquatic ecosystem, but it is unlikely to be sufficient. Our study clearly showed that even when all the potential chemicals were considered, unexpected acute lethal impact and chronic reproductive/growth failure could occur, which might lead to serious ecological consequences. It should be also mentioned that the correspondence between chemical parameters and resulting aquatic toxicities would be likely to be worse if the wastewater source should not be closely matched to the current Korean numeric parameters, which is the case for, e.g., organic-rich effluents such as paper and pulp wastewater. As such, the current chemistry-based effluent regulation should be supplemented with biologically risk-based approaches.

\section{REFERENCES}

APHA (American Public Health Association) (1992) Standard methods for the examination of water and wastewater, 18th ed. APHA, Washington, DC

Choi K, Meier PG (2000) Implications of chemical-based regulations in assessing DNA damage in fathead minnows (Pimephales promelas) when exposed to metal plating wastewater. Bull Environ Contam Toxicol 64:716-722

Fleiss JL (1981) Statistical methods for rates and proportions. 2nd ed. John Wiley \& Sons, New York, NY

Hockett JR, Mount DR (1996) Use of metal chelating agents to differentiate among sources of acute aquatic toxicity. Environ Toxicol Chem 15:1687-1693

Korea Ministry of Environment (2002) A study on development of management policy for aggregated toxicity of hazardous substances in water. Ministry of Environment, Gwacheon, Gyeonggi-do, Korea (In Korean) 
Landis JR, Koch GG (1977) The measurement of observer agreement for categorical data. Biometrics 33:159-174

Lee S, Shim J, Kim Y, Roh J (1991) Ecotoxicological and mutagenicity evaluation of industrial effluents with aquatic organisms (Oryzias latipes, Daphnia magna, Selenastrum capricornutum) and Ames' test with Salmonella J Kor Soc Wat Pollut Res Contr May 1991:100-109 (In Korean with English abstract)

Microbics Corp. (1992) Microtox ${ }^{\circledR}$ manual: a toxicity testing handbook, volume II detailed protocols. Microbics Corp., Carlsbad, CA

Munkittrick KR, Power EA, Sergy GA (1991) The relative sensitivity of Microtox ${ }^{\circledR}$, daphnid, rainbow trout, and fathead minnow acute lethality tests. Environ Toxicol Water Qual 6:35-62

Norberg-King TA (1993) A linear interpolation method for sublethal toxicity: the inhibition concentration (ICp) approach (version 2.0). National Effluent Toxicity Assessment Center Technical Report 03-93. US EPA, Environmental Research Laboratory, Duluth, MN

US EPA (1991) Technical support document for water quality-based toxics control. EPA/505/2-90-001, Office of Water, Washington, DC

US EPA (2002a) Methods for measuring the acute toxicity of effluents and receiving waters to freshwater and marine organisms, 5th ed. EPA-821-R-02012, Office of Research and Development, Washington, DC

US EPA (2002 $b$ ) Short-term methods for estimation of the chronic toxicity of effluent and receiving waters to fresh water organisms, 4th ed. EPA-821-R02-013, Office of Research and Development, Washington, DC 